\title{
ESTIMATION OF GENETIC PARAMETERS AND GENETIC TREND FOR KLEIBER RATIO IN BARKI SHEEP
}

\section{M. Ismail}

\author{
Animal and Poultry Breeding Dept., Desert Research Center, El-Matareya, Cairo, Egypt
}

\section{SUMMARY}

The present study was carried out to estimate genetic parameters and genetic trendforKleiber ratios (average daily gain from birth to weaning (3 month)/ metabolic weight (KR1), from weaning to 6 months old/ metabolic weight (KR2) and from 6 months to 9 months old/ metabolic weight (KR3)) in Barki sheep. Records of 1176 lambs of both sexes, progenies of 83 sires and 690 dams were used. Data were collected during 1997 to 2004 from the Barki sheep flock raised at the Desert Research Centre, Maryout Research Station, near Alexandria, Egypt. This flock was raised under a semi-intensive production system. The statistical analysis was carried out using restricted maximum likelihood methods. The model included sex, year of birth and dam's age as fixed effects in addition to animal, sires and dams as random effects. All these fixed effects were significant for all the studied traits. The heritability $\left(h^{2}\right)$ estimates for KR1, KR2 and KR3 were 0.15, 0.14, and 0.08, respectively. Genetic correlations were found to be high and significant for all traits under study. The results suggest that genetic improvement of efficiency of feed utilisation in Barki sheep through selection program based on Kleiber ratio is not expected to be efficient due to low heritability of the trait.

\section{Keywords: Barki lambs, kleiber ratio, Direct heritability and Genetic trend}

\section{INTRODUCTION}

Barki sheep are raised under a pastoral production system in the north western desert of Egypt with population of 493,000 (11\% of total Egyptian sheep population), and known to be well adapted to harsh desert conditions (MALR, 2014). A strategy to increase the efficiency of sheep production in conventional system as well as intensive systems is the selection of animals on the basis of efficiency of feed utilization. Since individual sheep differ in their ability to utilize feed efficiently, selecting the most efficient animals, those with lower maintenance requirements, results in a significantly lower production cost (Ghafouri-Kesbi et al., 2011). Direct selection for lower maintenance requirements is difficult. However, measures of feed efficiency could be used to achieve this goal (Arthur et al., 2001).

Kleiber ratio is defined as: growth rate divided by body mass ${ }^{0.75}$ (metabolic weight). It has been recommended as an indirect selection for feed conversion (Kleiber, 1947; and Köster et al., 1994). Previous results showed that a part of variation among animals concerning the $\mathrm{KR}$ is weakly heritable $\left(h^{2}=0.01-0.15\right)$. Furthermore, there is a positive genetic correlation of $\mathrm{KR}$, with traits related to growth (Abegaz, 2005; and Ghafouri-Kesbi et al., 2011). Although, genetic parameters for Kleiber ratio have been estimated for some breeds of sheep (Mohammadiet al., 2010, Savar-Soflaet al. 2011, and Mokhtariet al., 2012), information on genetic parameters for Kleiber ratio in Barki sheep is not available. Therefore, the aim of this research was to investigate genetic parameters and genetic trend for Kleiber ratio in Barki sheep in Egypt.

\section{MATERIALS AND METHODS}

\section{Source of data:}

Live body weight records of Barki lambs were collected from 1997 to 2004. Data were collected from Barki sheep flock, belonged to the Desert Research Center at Maryout Research Station, $35 \mathrm{~km}$ west of Alexandria. The animals of this flock were raised under a semi-intensive production system. Animals were allowed to pasture on residual of plants and crops or Egyptian clover in winter and the green maize in summer for 5 hours daily. A complementary ration was added to feed animals at the end of afternoon to ensure covering their daily requirements

Mating season took place in September, and lambing started in February each year. Ewes were often first mated at approximately 16-18 months of age. Mating groups of 20-25 ewes with one ram that was randomly chosen, were assigned during the mating season. At birth, lambs were ear-tagged and kept with their mothers and weighed within 24 hours after birth and at biweekly intervals thereafter until weaning. The lambs were weaned at 3 months. Detailed feeding and flock management was described by El-Wakil et al. (2009).

\section{Studied traits:}

Kleiber ratios were calculated as $\mathrm{KR} 1=\mathrm{ADG} 1 / \mathrm{WW}^{0.75}, \quad \mathrm{KR} 2=\mathrm{ADG} 2 / \mathrm{W}^{0.75}$ and $\mathrm{KR} 3=\mathrm{ADG} 3 / \mathrm{W} 9^{0.75}$ where, $\mathrm{ADG}=$ Average daily gain, $\mathrm{W}^{0.75}=$ metabolic weight, KR1 (from birth to weaning), KR2 (from weaning to 6 months old) and KR3 (from 6 months to 9 months old). Records of 1176 lambs descended from 83 rams and 690 ewes were included in the analysis. The characteristics of the data structure for KR1, KR2 and KR3 are shown in Table (1). 
Table 1. Characteristics of the data structure

\begin{tabular}{lccc}
\hline & KR1 & KR2 & KR3 \\
\hline No. of Records & 1176 & 980 & 783 \\
No. of male & 580 & 471 & 351 \\
No. of female & 596 & 509 & 432 \\
Mean & 16.7 & 8.12 & 4.74 \\
Standard deviation & 1.94 & 1.39 & 1.61 \\
Coefficient of variation \% & 11.64 & 17.08 & 33.96 \\
\hline
\end{tabular}

KR1, KR2, KR3 = Kleiber ratio

\section{Statistical analysis:}

Data were analyzed by the General Linear Model via the Statistical Analysis System (SAS, 2002), to estimate effect of ram, ewe within ram, year of birth, sex of lamb on growth criteria: KR1, KR2 and KR3. A statistical model used to analyze these data was written as:

$\mathrm{Y}_{\mathrm{ijklm}}=\mu+\mathrm{S}_{\mathrm{i}}+\mathrm{D}_{\mathrm{j}}+\mathrm{Y}_{\mathrm{k}}+\mathrm{G}_{\mathrm{l}}+\beta_{(\mathrm{age} \mathrm{of} \mathrm{dam}) \mathrm{ijklm}}+\mathrm{e}_{\mathrm{ijklm}}$ where:

$\mathrm{Y} 1=$ the observed records on the criterion (LBW)

$\mu \quad=$ the overall mean

$\mathrm{S}_{\mathrm{i}} \quad=$ the random effect of $\mathrm{i}^{\text {th }}$ ram, $\mathrm{i}=1, .$, ??,

$D_{j}=$ the random effect of $j^{\text {th }}$ ewe within ram, $\mathrm{j}=1, ., ?$ ?

$\mathrm{Y}_{\mathrm{k}}=$ the fixed effect of $\mathrm{k}^{\text {th }}$ year of birth, $\mathrm{k}=$ $1, ., 8$

$\mathrm{G}_{1}=$ the fixed effect of $1^{\text {th }} \operatorname{sex}$ of lamb, $1=1,2$

$\beta_{\text {agew }}=$ the linear regression coefficient of $\mathrm{KR}$ on age at dam as a covariate

$\mathrm{e}_{\mathrm{ijklmno}}=$ residual random error.

Estimation of variance components, genetic parameters and estimated breeding values (EBV) via BLUP (Best Linear Unbiased Prediction) were carried out by derivative-free REML with a simplex algorithm using the Multiple Trait Derivative-Free Restricted Maximum Likelihood [MTDFREML] (Boldman et al., 1995). Models in matrix notation were as follow:

Where:

$$
\mathrm{Y}=\mathrm{X} \beta+\mathrm{Z}_{\mathrm{a}} \mathrm{a}+\mathrm{e}
$$

$\mathrm{Y}=$ vector of observations (KR1, KR2. KR3),

$\mathrm{X}=$ incidence matrix for fixed effects and covariates $\beta=$ vector of fixed effects and covariates (i. e. fixed effect $=$ year of birth, and sex of lamb; covariate $=$ age of dam)

$\mathrm{Z} \quad=$ incidence matrix for random effects

$\mathrm{a}=$ vector of random effects (additive genetic effect)

$\mathrm{e}=$ vector of residual effects $\left(0, \mathrm{I} \sigma^{2}{ }_{\mathrm{e}}\right)$.

Genetic trends based regressing the means of predicted breeding values on year of birth were achieved. Genetic trend analyses were performed with the regression procedure of the SAS.

\section{RESULTS AND DISCUSSION}

Means, standard deviations and coefficients of variation for investigated trait are presented in Table (1). Kleiber ratio means of KR1, KR2, and KR3 were 16.7, 8.12, and 4.74, respectively. However, the results obtained by Ghafouri-Kesbi (2013) in Iranan Mehraban sheep were 19.6, 12.2 and 7.8, respectively; but Abegazet al. (2005) have reporter that KR1, KR2 were 15.3 and 4.4, respectively in Horro sheep. KR1 means were estimated as, 20.3, 18.5, 14.4 and 22.4 for Shal sheep (Mohamadi et al., 2013), Arman sheep (Moktari et al., 2013), Arabi Sheep (Roshanfekr 2014) and Romney sheep (FaidAllah et al., 2016) respectively. These differences in results may be due to differences in animal weights, breed and management.

Estimates of least squares means and SE for the studied traits are shown in Table 2. All these variables were significant $(\mathrm{P} \leq 0.05)$ for all studied traits. Also, the model included the animal, sire and dam as random effects were fitted for each trait. 
Table 2. Least square means \pm standard error for traits

\begin{tabular}{cccc}
\hline Sub-class & KR1 & KR2 & KR3 \\
\hline Sex & & & \\
Male & $16.78 \pm 0.07$ & $8.49 \pm 0.06$ & $5.32 \pm 0.07$ \\
Female & $16.78 \pm 0.07$ & $8.54 \pm 0.06$ & $5.23 \pm 0.06$ \\
Birth year & & & \\
$\mathbf{1}$ & $16.89 \pm 0.11^{\mathrm{c}}$ & $7.86 \pm 0.09^{\mathrm{b}}$ & $4.97 \pm 0.10^{\mathrm{bc}}$ \\
$\mathbf{2}$ & $16.10 \pm 0.13^{\mathrm{b}}$ & $10.35 \pm 0.11^{\mathrm{f}}$ & $6.48 \pm 0.12^{\mathrm{f}}$ \\
$\mathbf{3}$ & $16.12 \pm 0.15^{\mathrm{b}}$ & $8.98 \pm 0.13^{\mathrm{e}}$ & $5.27 \pm 0.14^{\mathrm{cd}}$ \\
$\mathbf{4}$ & $17.01 \pm 0.14^{\mathrm{c}}$ & $8.77 \pm 0.12^{\mathrm{de}}$ & $4.91 \pm 0.13^{\mathrm{b}}$ \\
$\mathbf{5}$ & $15.15 \pm 0.16^{\mathrm{a}}$ & $8.47 \pm 0.13^{\mathrm{cd}}$ & $5.98 \pm 0.14^{\mathrm{e}}$ \\
$\mathbf{6}$ & $17.27 \pm 0.15^{\mathrm{c}}$ & $7.33 \pm 0.13^{\mathrm{a}}$ & $4.39 \pm 0.14^{\mathrm{a}}$ \\
$\mathbf{7}$ & $17.89 \pm 0.16^{\mathrm{d}}$ & $7.97 \pm 0.14^{\mathrm{b}}$ & $4.81 \pm 0.15^{\mathrm{b}}$ \\
$\mathbf{8}$ & $17.80 \pm 0.17^{\mathrm{d}}$ & $8.14 \pm 0.14^{\mathrm{c}}$ & $5.41 \pm 0.15^{\mathrm{d}}$ \\
\hline
\end{tabular}

a,b,c,d are superscripts within a column differ at $(P<0.05)$, while e and, f superscript within a column are significant at $(P<0.01)$.

Table (3) showed that heritability estimates $\left(h^{2}\right)$ for KR1, KR2 and KR3, were $0.15,0.14$, and 0.08 , respectively, which approached the range reported for different breeds of sheep (Mohammadi et al., 2010, Ghafouri-Kesbi et al., 2011, Savar-Sofla et al., 2011, Mokhtari et al., 2012). For pre-weaning KR, estimates of $h^{2}$ ranged from 0.04 in Arman sheep (Mokhtari et al., 2012) to 0.15 in Sanjabi sheep (Mohammadi et al., 2010). For post-weaning KR, estimates ranged between 0.01 in Moghani sheep (Savar-Sofla et al., 2011) to 0.10 in Zandi sheep (Ghafouri-Kesbi et al., 2011). Heritability estimates for a trait can differ between sheep breeds and may change slowly over time.

Literature estimates of $h^{2}$ in sheep revealed that, the Kleiber ratio is a substantially low heritable trait. In goats, reports (0.13-0.35) are a bit higher than in sheep (Van Niekerk et al., 1996; and Supakorn and
Pralomkarn, 2012). In beef cattle, higher estimates of $h^{2}$ for Kleiber ratio have been reported. For example, Köster et al. (1994) reported estimates of $h^{2}$ ranging from 0.22 (KR at 205 days of age) to 0.54 (KR at 365 days of age) in Herford breed. According to current results, pre- and post-weaning Kleiber ratios in Barki sheep are categorized as low heritable traits. Therefore, a low genetic progress would be expected through selection programmes.

If a trait is only $10 \%$ heritable, then $90 \%$ of differences between animals would have been of non-genetic origin. For low heritable traits, where $h^{2}$ is below 0.15 , an animal's performance is much less useful for identifying the individuals with the best genes for the trait (Cassel, 2009). For this reason, selection for Kleiber ratio in sheep should be according to estimates of breeding values (Janssens and Vandepitte, 2004).

Table 3. Variance components and heritability estimates for traits studied

Traits Variance components

\begin{tabular}{lccccc} 
& $\sigma^{2}{ }_{\mathrm{a}}$ & $\sigma_{\mathrm{m}}^{2}$ & $\sigma_{\mathbf{p}}^{2}$ & $h^{2}(\mathrm{SE})$ & $\sigma_{\mathrm{e}}^{2}(\mathrm{SE})$ \\
\hline KR1 & 0.464 & 2.684 & 3.149 & $0.15(0.06)$ & $0.85(0.06)$ \\
KR2 & 0.199 & 1.214 & 1.414 & $0.14(0.07)$ & $0.86(0.07)$ \\
KR3 & 0.151 & 1.838 & 1.989 & $0.08(0.08)$ & $0.92(0.08)$
\end{tabular}

$\sigma_{\mathrm{a}}^{2}=$ direct additive genetic variance, $\sigma_{\mathrm{m}=}^{2}$ maternal additive genetic variance, $\sigma_{\mathrm{p}}^{2}=$ phenotypic variance, $h^{2}=$ direct heritability, and $\sigma_{\mathrm{e}=}^{2}$ residual variance ( $\mathrm{SE}=$ stander error) 
Table (4) showed that estimates of genetic correlations between traits were found to be highly significant for KR3-KR1 (-0.29) and KR3-KR2 $(0.22)$ and significant for KR1-KR2 (-0.05). The genetic correlation values between traits are not affected by the values of heritability, i.e. two traits can have a very high genetic correlation even when the heritability of each is low (Ghafouri-Kesbi. 2013).

The genetic correlations between KR3 \& KR2 $(0.22)$ are highly positive, possibly can therefore be used as the selection criteria of lambs with higher biological efficient and good users of feed are highly efficient to enhance the biological efficiency of the animals of the flock. These results are very important because Barki sheep use the pasture to cover maintenance and production. The negative genetic correlation estimates between KR1 and KR3 ensured the importance of neglecting using KR1 to select KR3.

The breeding value (BV) of a sire and ewe expressed a prediction of its genetic ability, which is very useful in any breeding program. The Kleiber ratios of BV (Table 5) had an indirect indication of the animal's genetic ability for efficiency of feed conversion. Animals with a higher breeding value are more efficient for selection. BV estimates (KR1, KR2 and KR3) in Barki sheep ranged from -0.505 to 0.558 for rams and -1.564 to 1.107 for ewes. These results agreed with those obtained by Faid-Allah et al. (2016) in Romney sheep. The negative estimates of the breeding values are appearing because of the absence of selection of animals of both sexes in this flock.

Table 4. Genetic correlation estimates between all traits in Barki sheep

\begin{tabular}{lccc} 
& KR1 & KR2 & KR3 \\
\hline KR1 & 1 & $0.052(*)$ & $-0.294(* *)$ \\
KR2 & 1 & $0.221(* *)$ \\
KR3 & & 1 \\
\hline$*$ Correlation is significant at the 0.05 level (2-tailed). & $* *$ Correlation is significant at the 0.01 level (2-tailed).
\end{tabular}

Table 5. Breeding values estimates for traits studied

\begin{tabular}{llcccc}
\hline & & \multicolumn{2}{c}{ Breeding values } & & \\
\cline { 3 - 5 } Sire & KR1 & Minimum & Maximum & Mean & Std \\
\hline \multirow{2}{*}{ EWE } & KR2 & -0.505 & 0.558 & 0.005 & 0.196 \\
& KR3 & -0.284 & 0.318 & -0.024 & 0.100 \\
& KR1 & -0.211 & 0.293 & -0.011 & 0.071 \\
& KR2 & -1.564 & 1.107 & -0.001 & 0.203 \\
& KR3 & -0.662 & 0.743 & 0.002 & 0.122 \\
\hline
\end{tabular}

The genetic trends were calculated by regression of average predicted breeding value for the studied trait of an animal within a year of birth. A negative estimate of the annual rate of genetic response from 4 to 6 years in the Barki sheep for studied KR traits was noticed. It may be due to the absence of genetic improvement strategy in this flock.

From one to eight years onwards, all traits have low BV tends, and the fluctuation in trends indicates bad selection program for this flock for the eight years under study. In case of KR2 and KR3 traits, slight increase in positive genetic trend was noted at the end of the studied years (Graph 1). Similar findings were reported by (Thiruvenkadan et al., 2011) and (Shokrollahi and Baneh, 2012), who mentioned similar results of genetic correlation coefficients and the breeding values of growth rate. 

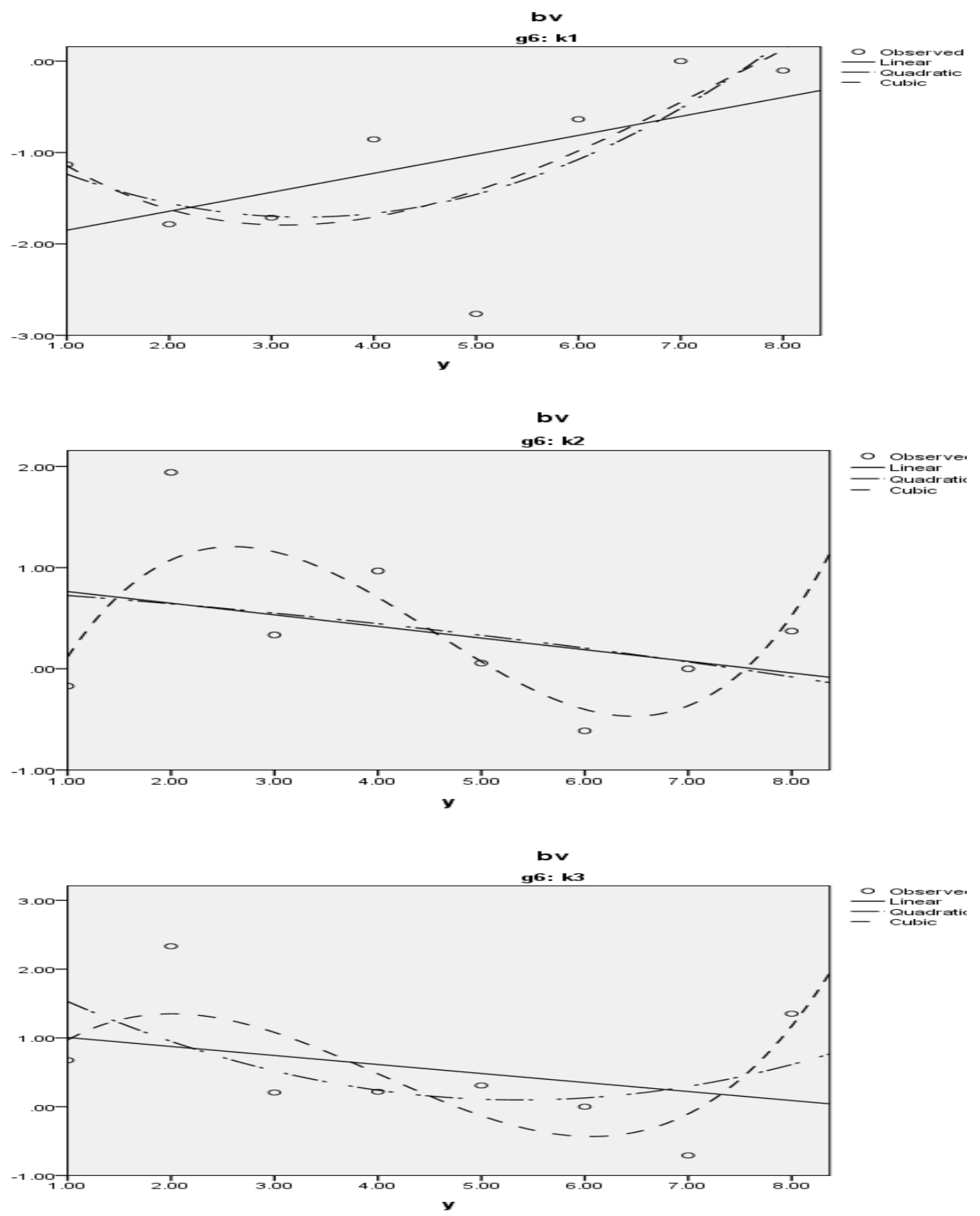

Fig 1: Genetic trends for Kalriber ratios in Barki sheep

\section{CONCLUSION}

Estimates of direct heritability and genetic correlations showed that genetic improvement in efficiency of feed utilisation through selection program is not expected to be effective for the studied flock of Barki Sheep.

\section{REFERENCES}

Abegaz, S., J.B. Van Wyk and J.J.Oliver, 2005. Model comparisons and genetic and environmental parameter estimates of growth and the Kleiber ratio in Horro sheep. South African Journal of Animal Science 2005, 35 (1), 30-40.

Arthur, PF, G. Renand andD. Krauss, 2001. Genetic and phenotypic relationships among different measures of growth and feed efficiency in young Charolais bulls. Livest Prod Sci 68, 131-139.

Boldman, K.G., L. A. Kriese, L.D.Van Vleck, C.P. Van Tassell and S.D. Kachman, 1995.A manual for use MTDFREML, A set of programs to obtain estimates of variances and covariance. U.S Department of Agriculture, Agricultural Research Service, Clay center, NE. 
Cassel B., 2009. Using Heritability for Genetic Improvement. Virginia Cooperative Exteension, Publication 404-084, College of Agriculture and Life Sciences. Virginia Polytechnic Institute and State University, USA http://pubs.ext.vt.edu/404/404-084/404-084 [last accessed 20.11.2013]

El-Wakil, Salwa I.; Manal Elsayed; A.M. Ahmed; R.R. Sadek and A.A. Nigm, 2009.Genetic and phenotypic parameters of birth, weaning and yearling body weights of Barki sheep raised in the north western coast of Egypt. Egyptian J. Anim. Prod., 46 (1): 43-52.

Faid-Allah E, E. Ghoneim,A.H.M.Ibrahim, 2016. Estimated variance components and breeding values for pre-weaning growth criteria in Romney sheep.JITV Vol. 21 No 2 Th. 2016: 73-82

Ghafouri-KesbiFarhad, 2013. (Co) variance components and genetic parameters for growth rate and Kleiber ratio in fat-tailed Mehraban sheep Archiv Tierzucht 56 (2013) 55, 564-572.

Ghafouri-Kesbi F, M.A.Abbasi, F. Afraz, M. Babaei,H. Baneh, R. AbdollahiArpanahi, 2011. Genetic analysis ofgrowth rate and Kleiber ratio in Zandi sheep. Trop Anim Health Prod 43, 11531159.

Janssens S. andW. Vandepitte, 2004. Genetic parameters for body measurements and linear type traits in Belgian Blue du Maine, Suffolk and Texel sheep. Small Rumin Res 54, 13-24

Kleiber M., 1947. Body size and metabolic rate.Physiol Rev 27, 511-541.

Köster E, J. van der Westhuizen, G.J. Erasmus, 1994. Heritability estimates for different Kleiber ratios obtained from growth performance data in a Hereford herd. S Afr J AnimSci 24, 71-72

MALR, 2014. Annual Statistic Book.Ministry of Agriculture and Land Reclamation. Egypt. Source, Animal Wealth Development Sector.Publisher, Economic Affairs Sector.

Mohammadi, K., A. Rashidi,. M.S. Mokhtari, and A.K. Esmailizadeh, 2010.Quantitative genetic analysis of growth traits and Kleiber ratios in
Sanjabi sheep.Small Ruminant Research. 93, 8893.

Mohammadi Hossein, Mohammad Moradi Shahrebabak, Hossein Moradi Shahrebabak, Abolfazl Bahrami and Mohammad Dorostkar, 2013. Model comparisons and genetic parameter estimates of growth and the Kleiber ratio in Shal sheep.Archiv Tierzucht 56 (2013) 26, 264-275.

Mokhtari M.S., M. Moradi Shahrebabak, H. Moradi Shahrebabk and M. Sadeghi, 2012.Estimation of (co)variance components and genetic parameters for growth traits in Arman sheep. J Livest. Sci Tech, 38-47

Roshanfekr Hedayatollah, 2014. Estimation of Genetic Parameters for Kleiber Ratio and Trends for Weight at Birth and Weaning in Arabi Sheep. Int. J. Adv. Biol. Biom. Res, 2014; 2 (11), 28302836.

SAS, 2002.User's Guide Statistics.Version 9.1, SAS Institute Inc, Cary, NC., USA.

Savar-Sofla S., A. Nejati-Javaremi, M.A. Abbasi,R. Vaez-Torshizi and M. Chamani, 2011.Investigation on Direct and Maternal Effects on Growth Traits and the Kleiber Ratio in Moghani Sheep. World ApplSci J 14, 1313-1319

Shokrollahi B. and H. Baneh, 2012.(Co) variance components and genetic parameters for growth traits in Arabi sheep using different animal models. Genetics and Molecular Research, 11(1): 305-314.

Supakorn C. andW. Pralomkarn, 2012. Genetic parameter estimates for weaning weight and Kleiber ratio in goats. Songklanakarin $\mathrm{J}$ SciTechnol 34, 165-172

Thiruvenkadan A. K., K. Karunanithi, J. Muralidharan and R. NarendraBabu, 2011. Gene tic analysis of pre-weaning and postweaning growth traits of Mecheri sheep under dry land farming conditions. Asian-Aust. J. Anim. Sci., 24(8):1041-1047.

Van Niekerk M.M, S.J. Schoeman, M.E. Botha, N. Casey, 1996. Heritability estimates for preweaning growth traitsin the Adelaide [South Africa] Boer goat flock. S Afr J AnimSci 26, 6-10
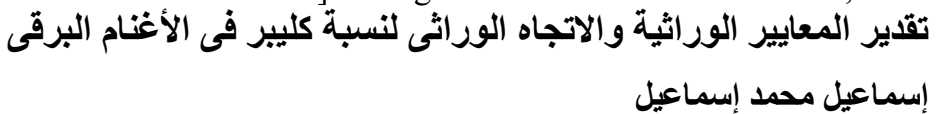

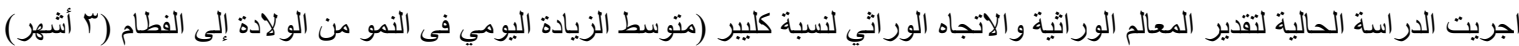

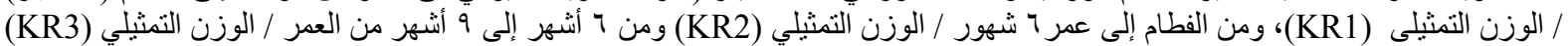

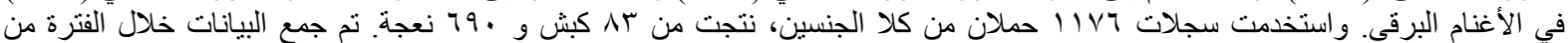

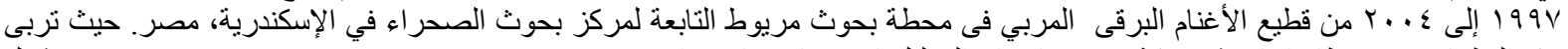

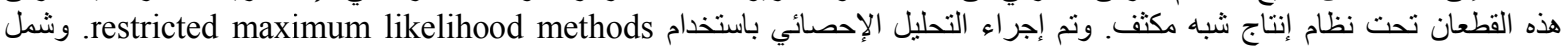

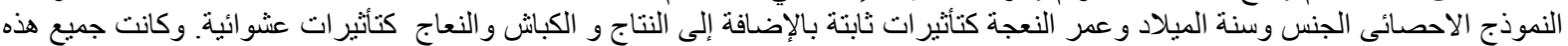

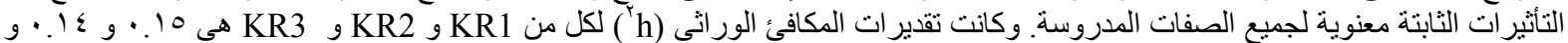

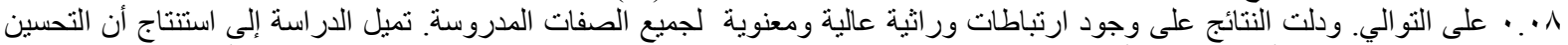

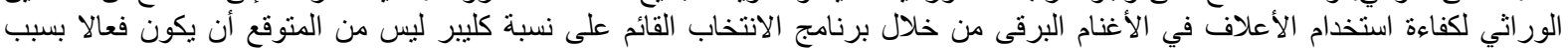
انخفاض المكافئ الور اثى لهذه الصفة. 